\title{
Acute helminth infection enhances early macrophage mediated control of mycobacterial infection
}

\begin{abstract}
N du Plessis ${ }^{1}$, L Kleynhans ${ }^{1}$, L Thiart ${ }^{1}$, PD van Helden ${ }^{1}$, F Brombacher ${ }^{2,3}$, WGC Horsnell ${ }^{2,3}$ and G Walzl ${ }^{1}$
Co-infection with mycobacteria and helminths is widespread in developing countries, but how this alters host immunological control of each pathogen is not comprehensively understood. In this study, we demonstrate that acute Nippostrongylus brasiliensis $(\mathrm{Nb})$ murine infection reduce early pulmonary mycobacterial colonization. This $\mathrm{Nb}-$ associated reduction in pulmonary Mycobacterium tuberculosis colony-forming units was associated with early and increased activation of pulmonary CD4 T cells and increased T helper type 1 (Th1) and Th2 cytokine secretion. An accelerated and transient augmentation of neutrophils and alveolar macrophages (AMs) was also observed in co-infected animals. AMs displayed markers of both classical and alternative activation. Intranasal transfer of pulmonary macrophages obtained from donor mice 5 days after $\mathrm{Nb}$ infection significantly reduced pulmonary Mycobacterium bovis Bacille Calmette-Guérin clearance in recipient mice. These data demonstrate that early stage $\mathrm{Nb}$ infection elicits a macrophage response, which is protective during the early stages of subsequent mycobacterial infection.
\end{abstract}

\section{INTRODUCTION}

Unrelated infections can influence a host's ability to optimally respond to each pathogen, as demonstrated by bacterial hyper-infections which frequently follow an influenza infection. ${ }^{1,2}$ Parasitic nematode infections such as hookworm and Ascaris lumbricoides, are common underlying infections in many areas ${ }^{3,4}$ and are likely to influence pulmonary immunity. ${ }^{5}$ How this exposure may alter host ability to control subsequent pulmonary bacterial infections is poorly understood, but extremely relevant, as the endemic distribution of helminths frequently overlap with areas where mycobacterial infections, such as Mycobacterium tuberculosis (M. tb), are prevalent. $^{6}$

Helminth infections induce strong $\mathrm{T}$ helper type 2 (Th2) immune responses while host control of $M$. $t b$ infection is associated with Th1 immunity. ${ }^{7,8}$ Th1 and Th2 immune responses can mutually antagonize each other; whether this translates to altered pathogen control in helminth-mycobacterial co-infection models is questionable. ${ }^{9,10}$ Current data indicate that helminth infections may impair immunity to M. $t b ;^{11,12}$ however, research into the mechanisms of such interactions remain contentious. This is supported by the association of elevated levels of Th2 cytokines, such as interleukin (IL)-4 and IL-13, with progressive tuberculosis (TB) disease ${ }^{7,13}$ and the positive correlation of total serum immunoglobulin $\mathrm{E}$ (also associated with Th2 immunity) and $A$. lumbricoides-specific immunoglobulin $\mathrm{E}$ with active TB., ${ }^{7,13,14}$ Studies in mice also show that Mycobacterium bovis Bacille Calmette-Guérin (BCG) vaccination efficacy can be impaired by chronic helminth infection. ${ }^{15}$ Moreover, it was reported that low-dose Schistosoma mansoni infection increased M. bovis BCG bacilli numbers and decreased Th1 immunity in coinfected mice. ${ }^{16,17}$ By contrast, Erb et al. ${ }^{18}$ demonstrated that the clearance of $M$. bovis in mice is unaffected by Nippostrongylus brasiliensis $(\mathrm{Nb})$ infection, indicating that pulmonary Th2 responses may not increase susceptibility to mycobacteria. Such conflicting outcomes are often observed during helminthmycobacterial co-infection, as reported by Potian et al. ${ }^{19}$ who

\footnotetext{
${ }^{1}$ Division of Molecular Biology and Human Genetics, MRC Centre for Molecular and Cellular Biology, DST/NRF Centre of Excellence for Biomedical TB Research, Faculty of Health Sciences, Stellenbosch University, Tygerberg, South Africa. ${ }^{2}$ International Centre for Genetic Engineering and Biotechnology, Cape Town, South Africa and ${ }^{3}$ Division of Immunology, Institute of Infectious Diseases and Molecular Medicine, Faculty of Health Sciences, University of Cape Town, Cape Town, South Africa. Correspondence: WGC Horsnell (wghorsnell@gmail.com); G Walzl (gwalzl@sun.ac.za)
} 
demonstrated that $\mathrm{Nb}$ infection, followed by infection with $M . t b$ on day 5 post helminth infection, decreased pulmonary $M$. $t b$ colony-forming units (CFU) early post infection (p.i.) but transiently increased $M$. $t b$ burden in co-infected mice at week 4 post $\mathrm{Nb}$ infection.

The current study investigated whether immunity to $M$. bovis BCG infection was altered by previous exposure to $N b$. The M. bovis BCG murine infection model is routinely used for studying anti-mycobacterial responses during latency as the associated immune response is similar to that induced during human $M$. $t b$ infection. ${ }^{20} \mathrm{Nb}$ infection serves as a model for hookworm infection that involves larval migration through the lung. ${ }^{21,22}$ Parasite movement from the circulatory to the bronchial system results in considerable pulmonary pathology and inflammation. ${ }^{23-25}$ This pathology is largely resolved by the host, but the overall immune potential in the lung shifts to a Th2 polarization. ${ }^{26}$ As the comparable human hookworm infections are common and recurrent, it may be hypothesisied that in hookworm endemic areas, such change in lung immunity may occur. In our study, we differentiate between how acute $\mathrm{Nb}$-induced lung pathology and long-term conditioning of the lung by the parasite influenced host ability to control mycobacterial infection. Mice were infected with $M$. bovis BCG during an active $\mathrm{Nb}$ infection or after the host had expelled $N b{ }^{27}$ We found that infection with $M$. bovis BCG during acute $\mathrm{Nb}$ infection led to reduced pulmonary bacilli burdens and that this effect was co-ordinated by alveolar macrophage (AM) responses.

\section{RESULTS}

BCG infection at day 5 post $N b$ infection reduces pulmonary mycobacterial burden in BALB/c mice independently of IL-4R $\alpha$ expression

Helminth-driven changes to host immunity and control of mycobacterial proliferation were established by infecting mice with M. bovis BCG at 5 days ("early") or 14 days ("late") post $N b$ infection. Mice were killed 2 and 14 days later. Viable pulmonary CFUs were equivalent between groups at day 2 post $M$. bovis BCG infection for both infection protocols (Figure 1 and Supplementary Figure S1). However, at day 14 post BCG infection, pulmonary CFU numbers from mice exposed to $\mathrm{Nb}$ for 5 days before BCG infection were significantly lower than BCG-only-infected mice (Figure 1). At this time point, all M. bovis BCG-infected IL- $4 \mathrm{R} \alpha^{-1-}$ mice displayed reduced pulmonary CFU numbers with a further reduction in CFU when co-infected with $M$. bovis BCG at day 5 post $N b$ infection (Supplementary Figure S1). Mice co-infected with BCG 14 days post $N b$ infection had equivalent pulmonary CFUs to those infected with $M$. bovis BCG only (Figure 1). These results show that active $\mathrm{Nb}$ infection reduced mycobacterial burden and that the $\mathrm{Nb}$ induced reduction in bacterial burden was independent of IL$4 \mathrm{R} \alpha$ and hence Th2 immune polarization. By contrast, the lung environment post helminth expulsion did not affect mycobacterial control.

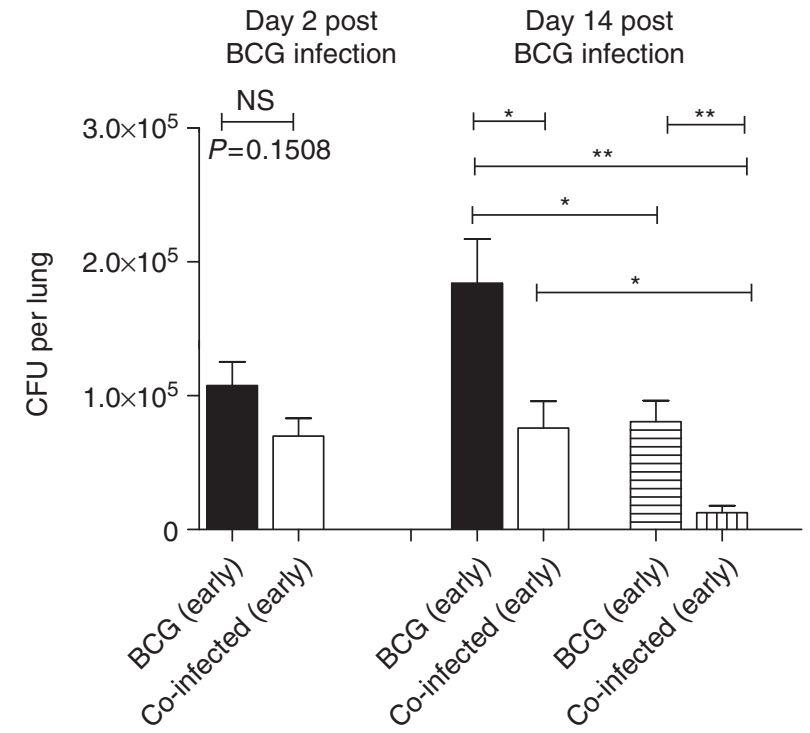

BCG-only (early) BALB/c Е BCG-only (early) IL-4R $\alpha^{-/-}$ $\square$ Co-infected (early) BALB/c एण Co-infected (early) IL-4R $\alpha^{-/-}$

Figure 1 Viable pulmonary Mycobacterium bovis Bacille CalmetteGuérin (BCG) colony-forming units (CFU) numbers displayed as mean \pm s.e.m. on days 2 and 14 post BCG infection of BALB/C and interleukin (IL)-4R $\alpha^{-1-}$ mice infected according to the "early" (BCG 5 days post Nippostrongylus brasiliensis $(\mathrm{Nb})$ infection) infection protocol. Groups included BCG-only infected and Nb/BCG co-infected mice. $\left({ }^{\star} P<0.05,{ }^{\star \star} P<0.01\right.$, ns, not significant).

\section{$\mathrm{Nb}-\mathrm{BCG}$ co-infection increases pulmonary pathology in BALB/c mice}

$\mathrm{Nb}$ larval migration through the lung results in pulmonary damage, leading to pathology resembling emphysema and chronic obstructive pulmonary disease. ${ }^{25}$ Intranasal (IN) infection of mice with $M$. bovis BCG induces pulmonary pathology in the form of cellular infiltration of macrophages and lymphocytes. ${ }^{20,28}$ We examined how these lung pathologies are affected by co-infection. Co-infection with $M$. bovis BCG at day 5 (early) post $\mathrm{Nb}$ infection showed a trend for increased $\mathrm{Nb}$-induced alveolar dilation (Figure 2). $\mathrm{Nb}$ also induced significantly increased pulmonary cellular infiltration in $\mathrm{Nb}$-only and co-infected mice (Figure 2). Co-infection with $M$. bovis $\mathrm{BCG}$ at day 14 (late) post $\mathrm{Nb}$ infection increased alveolar dilatation when compared with $\mathrm{Nb}$-only-infected mice (Supplementary Figure S2). $\mathrm{Nb}$ infection also increased pulmonary inflammation in both $\mathrm{Nb}$-only and co-infected mice (Supplementary Figure S2).

\section{$N b$ pre-infection increases early Th1 and Th2 cytokine responses in lung homogenates of co-infected mice} IFN- $\gamma$ and IL-13 cytokines are markers of Th1 and Th2 immune responsiveness, respectively. ${ }^{29,30}$ At day 2 post BCG infection, ex-vivo cytokine measurements of lung homogenates of the "early" infection protocol showed increased IFN- $\gamma$ concentrations in co-infected mice, compared with naive mice and BCG-only-infected mice (Figure 3a). Here the highest IFN- $\gamma$ concentrations were found in lung homogenates of 
$\mathrm{Nb}$-only-infected mice with levels significantly higher than all the other groups in the "early" infection protocol (Figure 3a). This indicates a heightened Th1 lung environment (in response to $\mathrm{Nb}$ infection) at the time of BCG infection. IL-13 levels from lung homogenates of each group in the "early" infection

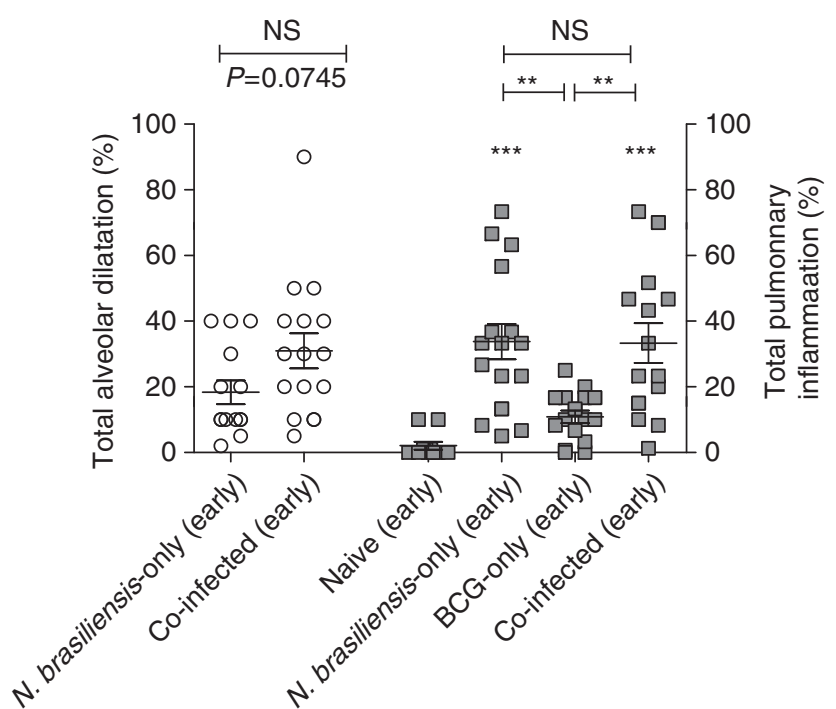

Figure 2 Total alveolar dilatation (clear circles) and total pulmonary inflammatory (gray squares) scores of BALB/c mice infected according to the "early" infection protocol. Data are displayed as means \pm s.e.m. Groups included naive, Bacille Calmette-Guérin (BCG)-only, Nippostrongylus brasiliensis-only, and co-infected. (ns, not significant, $\left.{ }^{\star \star} P<0.01,{ }^{* \star \star} P<0.001\right)$.
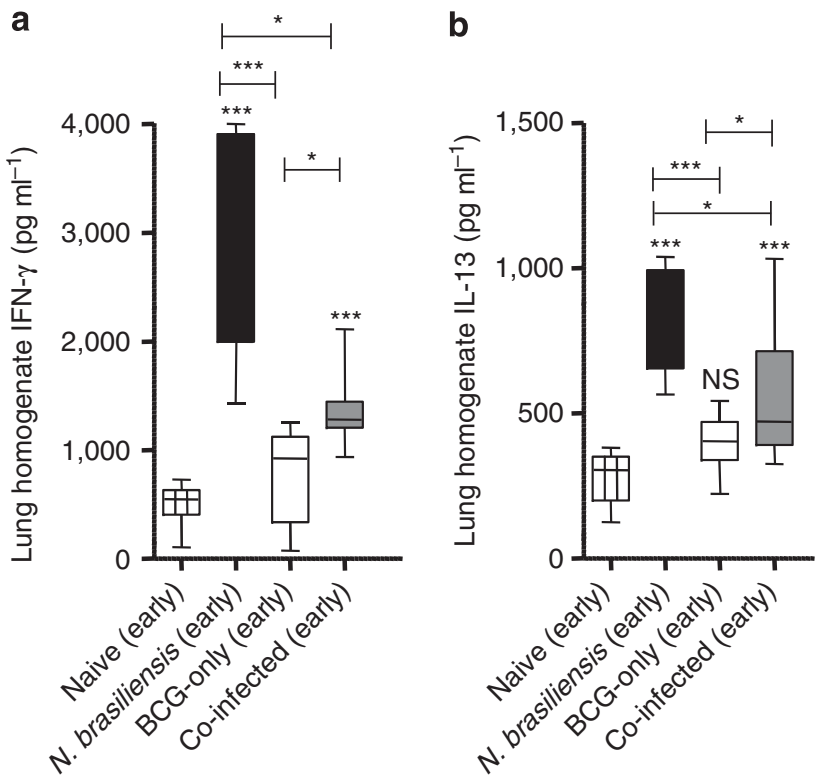

Figure 3 Ex-vivo pulmonary cytokine measurements. (a) Interferon (IFN)- $\gamma$ and (b) interleukin (IL)-13 cytokine concentrations measured from lung homogenates of BALB/c mice infected according to the "early" infection protocol. Data represent min-max values from two individual experiments as measured on day 2 post Bacille Calmette-Guérin (BCG) infection. Groups included naive (striped bars), Nippostrongylus brasiliensis-only (solid bars), BCG-only (clear bars), and co-infected (gray bars) mice. $\left({ }^{\star} P<0.05,{ }^{\star *} P<0.01,{ }^{\star \star *} P<0.001\right)$. protocol reflected the pattern observed for IFN- $\gamma$ concentrations (Figure 3b). Unexpectedly, in the early infection protocol, both Th1 and Th2 immunity was significantly reduced in co-infected compared with $\mathrm{Nb}$ only-infected mice. This reduction in cytokine responses in co-infected mice may be due to induction of T-cell exhaustion due to co-infection or induction of regulatory T-cell responses.

By contrast, IFN- $\gamma$ levels in lung homogenates from mice of the "late" infection protocol were largely equivalent between groups but reduced when compared with the corresponding groups of the "early" infection protocol (Supplementary Figure S3A). IL-13 levels remained significantly higher in $\mathrm{Nb}$ only and co-infected mice from the "late" infection protocol but displayed a significant reduction in absolute IL-13 levels when compared with all the corresponding groups of the "early" infection protocol (Supplementary Figure S3B).

\section{Spleen and lymph node BCG-specific IFN- $\gamma$ responses are enhanced following $\mathrm{Nb}$-BCG co-infection}

Antigen-specific IFN- $\gamma$ secretion by BCG-restimulated cells is considered a marker of protective Th1 immunity to mycobacteria. We investigated any association of M. bovis BCGspecific immune responses with the reduced mycobacterial burden observed in co-infected mice of the "early" infection protocol at day 14 post BCG infection. Here BCG-specific IFN- $\gamma$ secretion was increased in spleen and mediastinal lymph nodes (MLN) cells of BCG-only and co-infected mice, when compared with the naive and $\mathrm{Nb}$-only infected groups

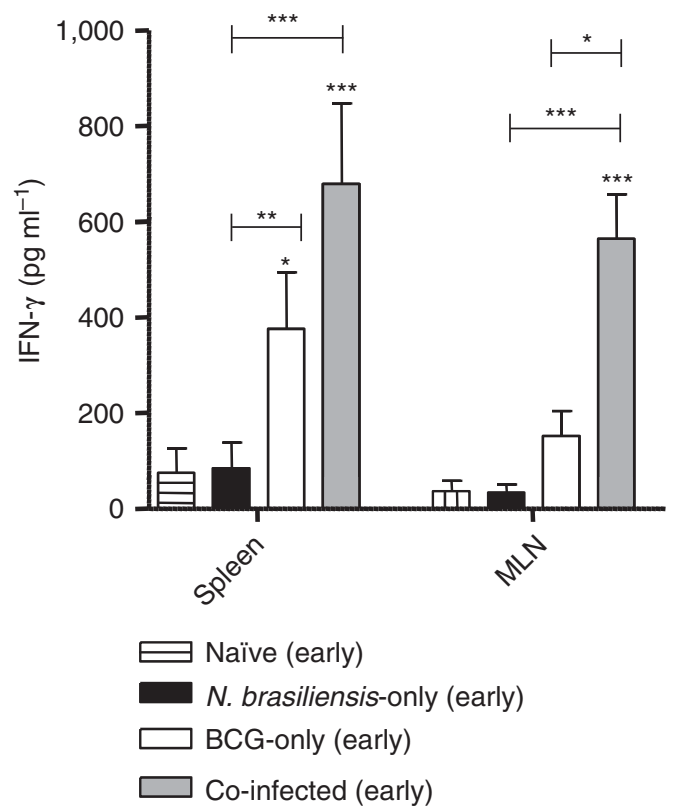

Figure 4 Interferon (IFN)- $\gamma$ cytokine values \pm s.e.m. from Bacille Calmette-Guérin (BCG)-stimulated splenocyte and mediastinal lymph nodes (MLN) culture supernatants of individual BALB/c mice measured on day 14 post BCG infection. Results represent data from two individual experiments corrected for background cytokine secretion by subtracting unstimulated control wells. Groups included naive (striped bars),

Nippostrongylus brasiliensis-only (solid bars), BCG-only (clear bars), and co-infected (gray bars) mice. ( ${ }^{\star} P<0.05,{ }^{\star \star} P<0.01$, $\left.{ }^{\star \star \star} P<0.001\right)$. 
(Figure 4). Co-infection also increased BCG-specific IFN- $\gamma$ secretion by MLN cells when compared with those of BCG-only infected animals (Figure 4). Nonetheless, $\mathrm{Nb}$ infection did not induce significant changes in long-lived IFN- $\gamma$ and IL-4 cytokine or memory responses by BCG-specific $\mathrm{T}$ cells in the lung at days 14 or 28 p.i., when compared with BCG-onlyinfected mice (Supplementary Figure S4A and B).

\section{$\mathrm{Nb}$ infection induces increased pulmonary T-cell populations and cytokine responses}

The early presence of pulmonary CD4 T-cell populations drives immunity to mycobacterial infections. ${ }^{31}$ In the "early" infection protocol, proportions of activated $\mathrm{CD} 4{ }^{+} \mathrm{CD} 44^{\text {hi }} \mathrm{T}$ cells in the lung were increased at the days 2 and 8 time points in $\mathrm{Nb}$-only and co-infected mice (Figure 5a). At day 14 p.i., total numbers of activated pulmonary CD4 $\mathrm{T}$ cells remained significantly increased in co-infected mice when compared with naive mice (Figure 5a).

Th1, Th2, and Th17 cytokine production by CD4 ${ }^{+} \mathrm{T}$ cells were highest in $\mathrm{Nb}$-only and co-infected mice at day 2 p.i., with concentrations of IFN- $\gamma$, IL-17, granulocyte macrophage colony-stimulating factor (GM-CSF), IL-4, IL-5, and IL-13 significantly higher than in BCG-only and naive mice (Figure $\mathbf{5 b}, \mathbf{c}$ ). At day 8 post BCG infection, $\mathrm{CD} 4{ }^{+} \mathrm{T}$-cell Th1 and Th2 cytokine production declined in co-infected mice but not in $\mathbf{N b}$-only-infected mice (Figure $\mathbf{5 b}, \mathbf{c}$ ). By day 14 post BCG infection, CD4 ${ }^{+}$T-cell Th1 (IFN- $\gamma$, GM-CSF) and Th17 (IL-17) cytokine production by BCG-only and co-infected mice displayed a dramatic increase, with levels significantly higher than those of the other groups (Figure $5 \mathbf{b}, \mathbf{c}$ ). CD $4^{+}$T-cell Th1 (GM-CSF), Th2 (IL-13, IL-5), and Th17 (IL-17) cytokine concentrations from $\mathrm{Nb}$-only-infected mice had reduced to
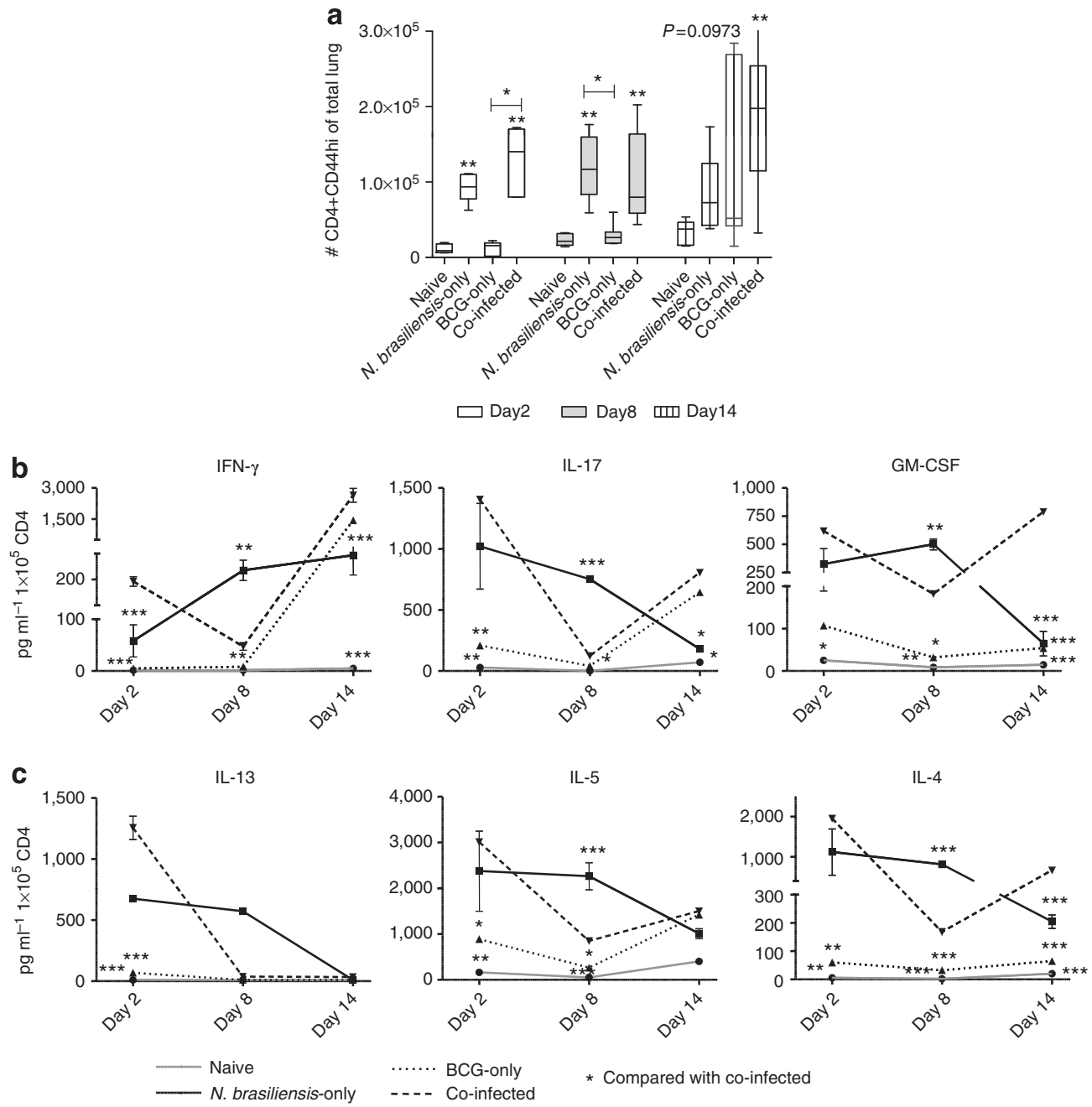

Figure 5 Pulmonary T cell phenotype. (a) Total numbers of activated pulmonary CD4 ${ }^{+}$T cells at days 2, 8, and 14 post Bacille Calmette-Guérin (BCG) infection as determined by flow cytometry. Mean and min-max values of at least 4-5 mice per group are shown. Groups included mice co-infected according the "early" infection protocol, Nippostrongylus brasiliensis (Nb)-only infected, BCG-only infected, and naive mice. Pulmonary CD4 ${ }^{+} \mathrm{T}^{-c e l l-}$ specific (b) Th1 and (c) Th2 cytokine responses following $8 \mathrm{~h}$ phorbol 12-myristate 13-acetate and lonomycin stimulation were measured by multiplex cytokine array from cell supernatants of individual lungs at days 2,8 , and 14 post BCG infection. Each point indicates the mean \pm s.e.m. results of at least five mice per group. Groups included mice co-infected according the "early" infection protocol (stripes), Nb-only infected (black), BCG-only infected (dotted), and naive (gray) mice. Cytokine values showing significant differences to those of co-infected mice at each time point are indicated. $\left({ }^{\star} P<0.05\right.$, $\left.{ }^{\star \star} P<0.01,{ }^{\star \star \star} P<0.001\right)$. GM-CSF, granulocyte macrophage colony-stimulating factor. 
levels observed for naive mice (Figure $\mathbf{5 b}, \mathbf{c}$ ). These results suggest an initial heightened quantity and quality of pulmonary Th1 and Th2 responses in co-infected vs. BCG-only-infected mice that declines by day 8 and then increased again at day 14 p.i. Although most Th1 and Th2 concentrations were equivalent between $\mathrm{Nb}$-only and co-infected mice at the day 2 time point, levels remained significantly higher in $\mathrm{Nb}$ only at day 8 and concentrations decreased significantly at the day 14 time point, when compared with co-infected mice.

\section{Co-infection accelerates and increases antigen-presenting cells and phagocyte numbers in BALB/c lungs}

Frequencies of AMs (Autofluorescent, $\mathrm{CD} 11 \mathrm{c}^{+}$) and neutrophils $\left(\mathrm{CD} 11 \mathrm{c}^{-} \mathrm{CD} 11 \mathrm{~b}^{+} \mathrm{Gr}-1^{+}\right)$were compared between all the groups of mice at serial time points for the "early" infection protocol. At day 2 post BCG infection, $\mathrm{Nb}$-only-infected mice displayed a significant increase and co-infected mice a trend for increased numbers of AMs with respect to those measured from naive and $M$. bovis BCG-only-infected mice (Figure 6a). At day 8 post BCG infection, both $\mathrm{Nb}$-only and co-infected mice had higher numbers of AMs when compared with naive and BCGonly-infected mice (Figure 6a). By day 14 post BCG infection, all the three infection groups displayed equivalent $\mathrm{AM}$ populations (Figure 6a). Mechanisms underlying $\mathrm{Nb}$-induced AM accumulation may be rapid influx of blood monocytes to the lung due to helminth tissue damage-induced chemokine/ cytokine production ${ }^{32}$ and/or Th2-driven local AM proliferation. ${ }^{33}$ Other antigen-presenting cells analyzed included neutrophils. The numbers of neutrophils in the lungs of co-infected and $\mathrm{Nb}$-only-infected mice were significantly increased at day 8 post BCG infection, when compared with those measured from naive and BCG-only-infected lungs (Figure $6 \mathbf{b}$ ).

\section{AMs from co-infected lungs display a combination of classical and alternative activation phenotype and cytokine profile, but retain $\mathbf{N b}$-induced morphology}

Classically activated macrophages (CAMs) are associated with nitric oxide and Th1 cytokine production and alternatively activated macrophages (AAMs) with increased arginase activity and production of Th2 cytokines. ${ }^{34}$ We measured these responses from AMs isolated from the "early" infection protocol. Results showed that AM production of type- 1 and type- 2 cytokines was equivalent to naive and BCG-onlyinfected groups at all time points. At day 2 post BCG infection, $\mathrm{Nb}$ infection induced significantly higher levels of AM-specific type-1 (IL-12) and type-2 (IL-5, IL-4) cytokines and a trend for increased GM-CSF in co-infected mice, when compared with BCG-only infected (Figure 7a,b). Similar results were observed for $\mathrm{Nb}$-only-infected mice at the day 2 time point (Figure $7 \mathbf{a}, \mathbf{b}$ ). By day 8 post BCG infection, AM-specific type- 1 and type- 2 responses remained significantly higher in co-infected mice in comparison to those of naive and BCG-only-infected mice, with type-1 levels showing stable and type-2 showing peak expression levels. At the same time point, AM-specific type-1 levels declined, whereas IL-5 and IL-13 levels were high in Nbonly-infected mice (Figure 7a,b). By day 14 post BCG infection, AM-specific type-1 cytokines from both coinfected and $\mathrm{Nb}$-only-infected mice continued to decline, with only co-infected mice displaying significantly higher IFN$\gamma$ and GM-CSF levels (Figure 7a). Day 14 AM type-2 cytokines were reduced in all the groups, but IL- 4 and IL-5 were still detected at higher levels from AMs of co-infected mice when compared with naive and BCG-only-infected mice (Figure 7b). These data show that in co-infected mice both Th1 and Th2 AM cytokine responses are increased when compared with BCG-only-infected mice. Significant differences in cytokine expression between $\mathrm{Nb}$-only and coinfected mice were only observed for GM-CSF at day 8 p.i.

AM-specific arginase responses were similar to the Th2 cytokine profiles of AMs (Figure 7c). At all time points, AM arginase from BCG-only-infected mice was equivalent to naive mice (Figure 7c). At days 2 and 8 post BCG infection, AM arginase expression in co-infected mice were significantly increased in comparison to BCG-only-infected mice, but by day 14 , levels were equivalent between co-infected, BCG-only, and $\mathrm{Nb}$-only-infected mice. AM arginase levels in $\mathrm{Nb}$-onlyinfected mice were higher than BCG-only, but less than co-
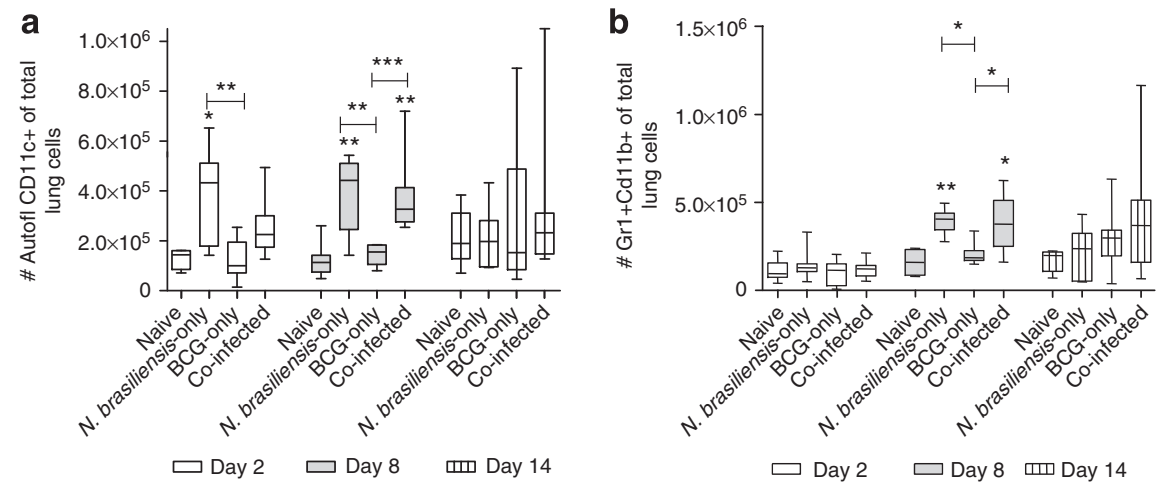

Figure 6 Pulmonary innate cell phenotype. (a) Total numbers of autofluorescent CD11c ${ }^{+}$alveolar macrophages per lung as determined by flow cytometry at days 2, 8, and 14 post Mycobacterium bovis Bacille Calmette-Guérin (BCG) infection from mice infected according to the "early" co-infection protocol. (b) Total numbers of $\mathrm{CD} 11 \mathrm{c}^{-} \mathrm{Gr} 1{ }^{+} \mathrm{CD} 11 \mathrm{~b}^{+}$neutrophils per lung as determined at days 2, 8, and 14 post $M$. bovis BCG infection from mice infected according to the "early" infection protocol. Means and min-max values of at least 4-5 mice per group are shown. Data are representative of two individual experiments per time point. $\left({ }^{\star} P<0.05,{ }^{\star \star} P<0.01\right.$, $\left.{ }^{\star * \star} P<0.001\right)$. 

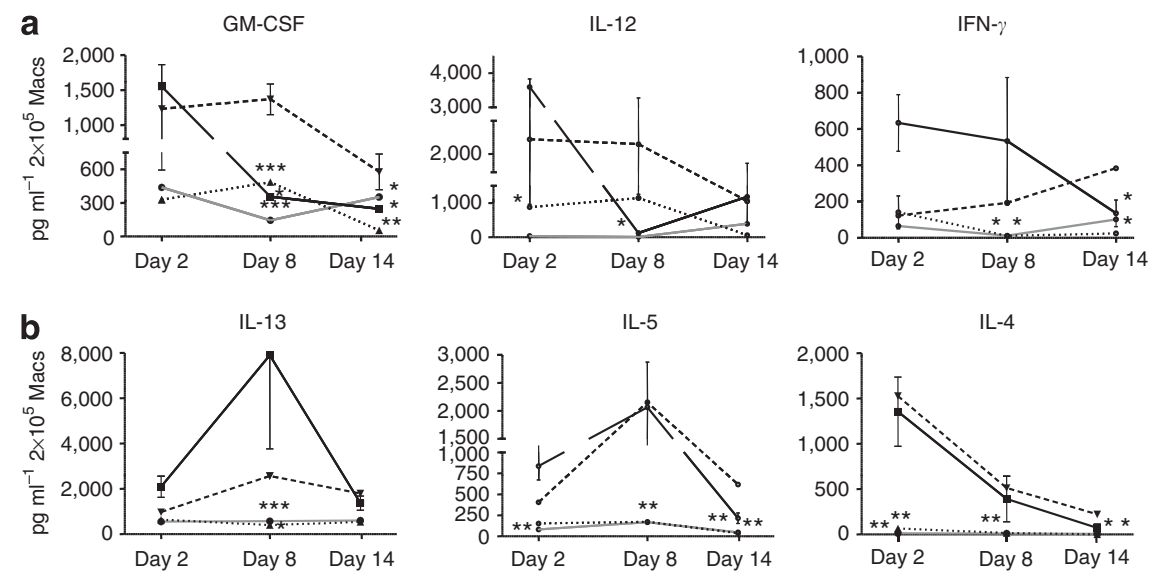

C

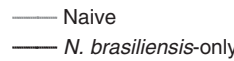

….. BCG-only $\quad$ * Compared with co-infected

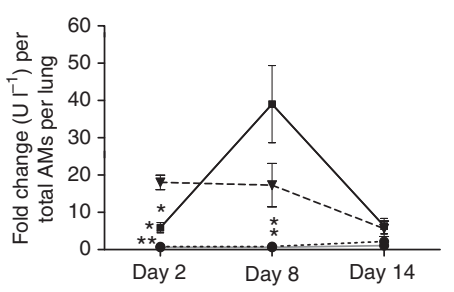

- Naive

BCG-only (early)

N. brasiliensis-only (early)

* Compared with co-infected

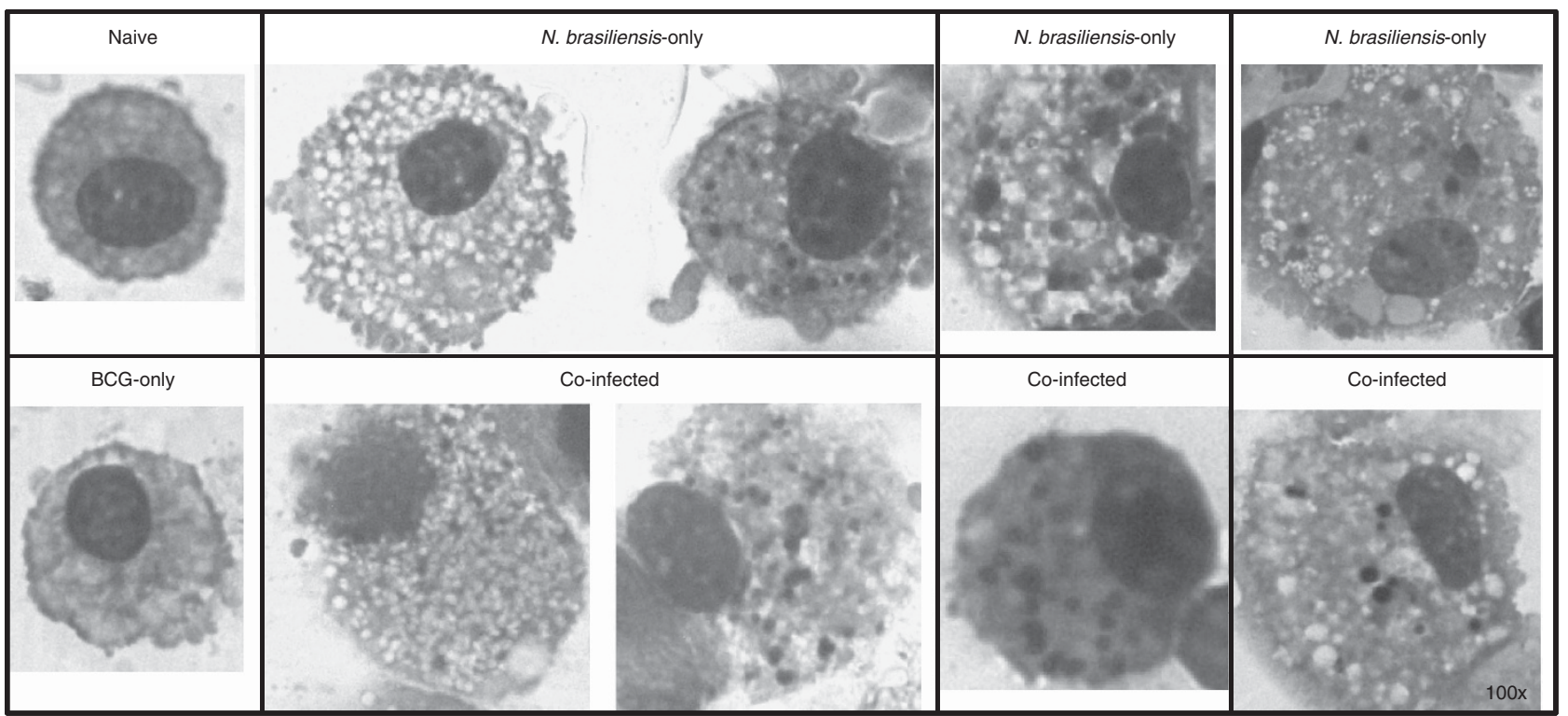

Figure 7 Alveolar macrophages (AMs) were collected through adherence on days 2, 8, and 14 post Bacille Calmette-Guérin (BCG) infection from the lungs of BALB/c mice infected according to the "early" co-infection protocol. (a) Type-1 cytokines, (b) type-2 cytokines and (c) arginase activity was measured from supernatants of the adherent cells after $6 \mathrm{~h}$ in culture. Results are representative of two independent experiments. Cytokine values showing significant differences to those of co-infected mice at each time point are indicated. $\left({ }^{\star} P<0.05,{ }^{* \star} P<0.01,{ }^{* * *} P<0.001\right)$. (d) At each time point, days 2, 8, and 14 post BCG infection, AMs were fixed on cytospin slides, stained with hematoxylin and eosin and examined by light microscopy to identify morphological changes introduced following infection according to the "early" co-infection protocol. GM-CSF, granulocyte macrophage colonystimulating factor; IFN, interferon; IL, interleukin.

infected at day 2, with peak levels measured at the day 8 time point and equivalent to the other groups at the day 14 time point (Figure 7c). Taken together, these cytokine and arginase profiles show that in co-infected mice, AM responses have characteristics of both CAM and AAM.

Morphological changes introduced to macrophages following infection demonstrated that AMs from BCG-only-infected mice displayed a small cell size with clear cytoplasm at all time points analyzed, similar to AM from naive mice (Figure 7d). By contrast, AMs from both co-infected and $\mathrm{Nb}$-only-infected mice displayed two distinct morphologies at day 2 p.i. These AMs were distinguished by a large cell size with either a vacuolated-only or a vacuolated and granular cytoplasm (Figure 7d). At days 8 and 14 , AMs of both the groups continued to display a vacuolated and granular cytoplasm (Figure 7d).

\section{$\mathrm{Nb}$-associated innate immune response induces in vivo, but not in vitro, BCG clearance in co-infected BALB/c mice}

In vitro macrophage uptake assays of $M$. bovis BCG were performed to simulate mycobacterial phagocytosis as experienced in murine lungs during co-infection or BCG-only infection, with the intent to establish the influence of helminthexposure on AM-mediated control of M. bovis BCG. Results from 3 and $20 \mathrm{~h}$ in vitro uptake assays showed no significant 

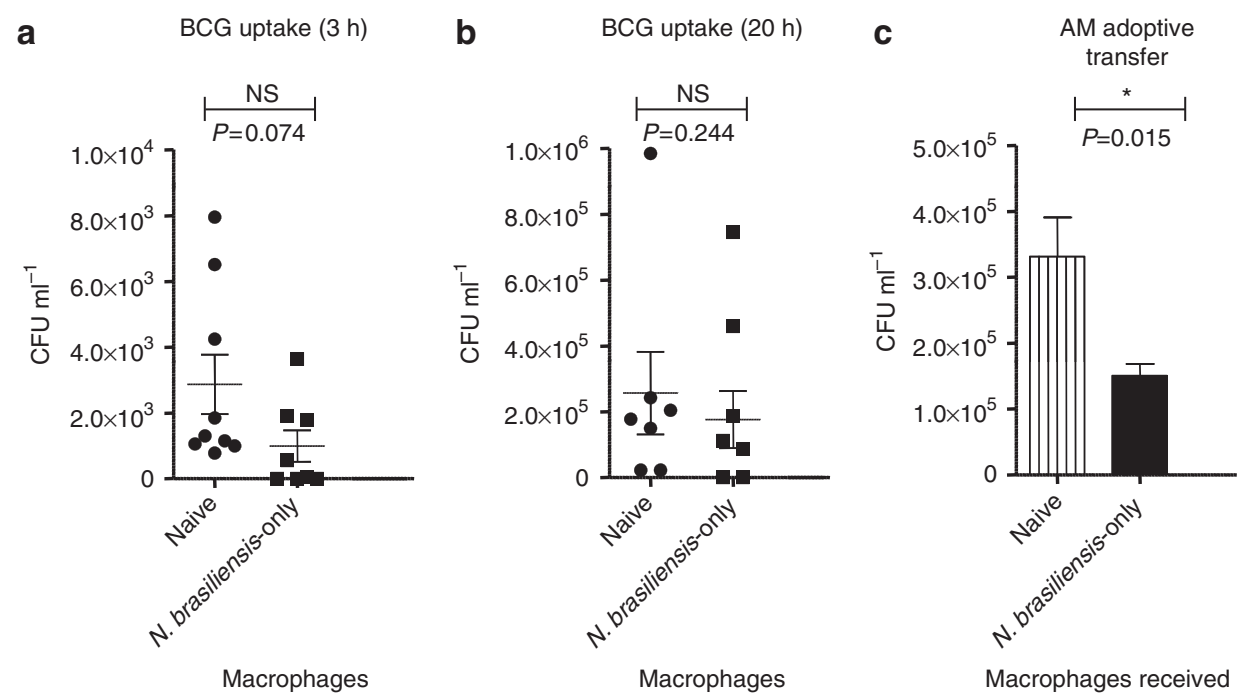

Figure 8 Intracellular colony-forming units (CFU) numbers of alveolar macrophages (AMs), isolated from naive (solid circle) or Nippostrongylus brasiliensis (Nb)-only (solid square) infected mice, exposed in vitro to Mycobacterium bovis Bacille Calmette-Guérin (BCG) bacilli (multiplicity of infection 10:1) for (a) $3 \mathrm{~h}$ or (b) $20 \mathrm{~h}$. Graphs indicate combined results of two experiments with means \pm s.e.m. (c) Pulmonary CFU numbers at day 14 post BCG infection. Balb/c mice were adoptively transferred intranasally (IN) with AMs from naive (striped bar) or day-5 Nb-only (solid bar) infected from mice 1 day before and 1 day after IN BCG infection. Data are displayed as means \pm s.e.m. (ns, non significant; ${ }^{*} P<0.05$ ).

difference in BCG uptake between AMs from $\mathrm{Nb}$-only-infected mice and uninfected naive mice (Figure 8a,b).

However, IN adoptive transfer of AM from either naive or $\mathrm{Nb}$-only-infected mice showed a significant reduction in pulmonary $M$. bovis BCG burden at week 2 post BCG infection in recipients of AMs from day $5 \mathrm{Nb}$-infected mice compared with those receiving AMs from uninfected mice (Figure 8c).

\section{DISCUSSION}

Increasing evidence indicates that infection with one pathogen will alter host immunity to infection by an unrelated pathogen. ${ }^{35,36}$ In this study, we demonstrated that previous helminth infection alters immunity to a subsequent mycobacterial infection. Unexpectedly, we found that early enhanced control of $M$. bovis BCG infection occurred in hosts with an active $\mathrm{Nb}$ infection. This enhanced control was associated with increased pulmonary AM and neutrophil numbers and the early induction of an activated pulmonary $\mathrm{CD} 4^{+} \mathrm{T}$-cell population. Concomitant with this was increased local and systemic $M$. bovis BCG-specific IFN- $\gamma$ responses.

$\mathrm{Nb}$ infections induce robust host adaptive Th2 polarization, the converse of Th1 immunity associated with control of mycobacterial infection. However, innate immunity induced by acute $\mathrm{Nb}$ infection enhancing immunity to a subsequent unrelated infection has been demonstrated previously. Acute $\mathrm{Nb}$ infection can enhance clearance of Plasmodium chabaudi parasites in mice through induction of non-specific IFN- $\gamma .{ }^{37}$ Although helminth-enhanced protection against $M$. $t b$ has not been widely reported, early stage $S$. mansoni infections have been associated with BCG vaccination-driven protection against $M$. $t b$, but as $S$. mansoni infection progressed, protection against $M . t b$ declined. ${ }^{15}$
These observations are in agreement with our data, namely that the early response to $N b$ provides an environment suitable to the control of $M$. bovis BCG. In support of this, we demonstrate strong Th1 cytokine responses in $\mathrm{Nb}-\mathrm{M}$. bovis BCG co-infected mice at day 2 post BCG infection. This was also accompanied by enhanced Th2 immunity, suggesting that $\mathrm{Nb}$ induced a hyper-responsive T-cell response. Such responses were apparent locally (lung) and systemically (lymph nodes), and both innate cellular and adaptive responses appeared to contribute to protection. Early increases in activated CD4 $\mathrm{T}$ cells in $\mathrm{Nb}$-only mice was lost by day 14 p.i., but co-infected mice showed an increased response at day 14, possibly representing a switch from a helminth-specific- to a BCGspecific-dominated $\mathrm{CD} 4 \mathrm{~T}$-cell response in the lung. This was substantiated by data showing that $\mathrm{Nb}$ does not affect IFN- $\gamma$ cytokine production by BCG-specific $\mathrm{T}$ cells in the lung at day 14 p.i.

In addition to the effects on T-cell responses, we also found that early type- 1 cytokine responses by AMs from co-infected mice are associated with reduced $M$. bovis BCG numbers. In support of a functional role for this macrophage response, we demonstrated that IN transfer of AMs from $\mathrm{Nb}$-infected mice was sufficient to reduce mycobacterial burden. However, in vitro studies suggest that this was not due to direct enhanced bacterial control by these macrophages. This would suggest a co-ordinating role for AMs in enhancing killing. In favor of this were increased levels of alternative and classical activation markers when compared with BCG-only-infected animals. Both AAMs and CAMs are well defined as having an important role in co-ordinating host immunity. ${ }^{38}$ We suggest that our data provides evidence of $\mathrm{Nb}$ driving a transient but fundamental change of function in the host's pulmonary macrophage population that could enhance co-ordination of other effector 
cell populations, such as neutrophils. ${ }^{39-41}$ Our observations of increased $\mathrm{Gr}^{+}{ }^{+} \mathrm{CD} 11 \mathrm{~b}^{+}$granulocytes in co-infected mice support this hypothesis. Previous reports of cross protection in co-infection implicate the early secretion of IFN- $\gamma$, activating macrophages, or IL-17-mediated mobilization of neutrophils, collectively enhancing innate immunity against a subsequent unrelated infection. ${ }^{42,43}$ We suggest a similar mechanism whereby $\mathrm{Nb}$ infection accelerates innate cell infiltration, activation, and cytokine production, enabling a non-specific but effective immune response to mycobacterial infection. The long interval between innate immunity to mycobacteria and the onset of protective immunity is considered a delayed response in comparison to those of other infections. ${ }^{44}$ The significance of the kinetics of immune response initiation to mycobacteria was demonstrated previously when accelerated protective immunity resulted in enhanced control of $M$. $t b$ infection in mice. ${ }^{45}$ Acute $\mathrm{Nb}$ infection would therefore protect against an ongoing intracellular infection by contributing to a state of heightened immunity. Potian et al. ${ }^{19}$ also demonstrated that mice co-infected with a virulent $M$. $t b$ strain (Erdman) on day 5 following $\mathrm{Nb}$ infection display a reduced pulmonary mycobacterial burden at week 2 post $M$. tb in comparison to $M$. $t b$-only-infected mice. Even though they reported a transient significant increase in pulmonary $M . t b \mathrm{CFU}$ in co-infected mice at week 4 , this subsequently returned to levels similar to those of $M$. $t b$-only-infected lungs by week 7 post M. $t b$ infection. ${ }^{19}$ Although it remains complicated to directly compare results from virulent and non-virulent mycobacterial strains, our data specifically corresponds to that of Potian et al. ${ }^{19}$ at the week 2 post $M$. $t b$ time point. An important point we address is that helminths not only induce a Th2 response but also a significant initial Th1 responses. ${ }^{19}$ The early combined presence of Th1 cytokines following $N b$ infection may therefore contribute to early control of $M$. bovis BCG infection by transiently accelerating activation and recruitment of CAM and neutrophils.

Our data on the morphological changes associated with AMs provide further evidence that AMs from co-infected mice also adopt features of a helminth-induced macrophage phenotype. $\mathrm{Nb}$ infection is known to induce formation of "foamy" highly vacuolated AMs that changes to a granulated phenotype as infection progresses. ${ }^{26}$ During $M$. $t b$ infection, induction of "foamy" macrophages are affected by the balance of GM-CSF and M-CSF in the pulmonary environment and has been linked to a decreased phagocytic ability, reduced TLR expression, inability to contain mycobacteria, and diminished production of pulmonary tumor necrosis factor- $\alpha$, MIP- $1 \alpha$ (macrophage inflammatory protein- $1 \alpha$ ), and MIP- $1 \beta{ }^{46-49}$ The presence of foamy macrophages in granulomas of TB patients has also been associated with high lipid content, providing nutrition to $M$. $t b$ bacilli, and in vitro experiments established that mycobacterialderived mycolic acids induce the transition of human monocyte-derived macrophages into foamy macrophages. ${ }^{50}$ However, in the current study, "foamy" AMs of co-infected mice also displayed conspicuous granules in the cytoplasm. Granular AMs have been linked to phagocytosis of apoptotic,
M. $t b$-infected neutrophils by surrounding AMs, resulting in decreased viability of intracellular M. $t b .{ }^{41}$ We speculate that the granular AMs observed in co-infected mice likely reflect increased phagocytosis of cellular debris created by $\mathrm{Nb}$ larval lung migration and consequently also their uptake of apoptotic mycobacterial-containing cells. These secondary in vivo conditions induced by $\mathrm{Nb}$-primed macrophages will, however, not be present in an in vitro system, clarifying why macrophagemediated protection was only observed in vivo.

Our observations do, however, indicate that this $N b$-mediated protection decreased by week 4 post $M$. bovis BCG infection, suggesting that subsequent enhanced control to be dependent on the development of pathogen-specific adaptive immunity (data not shown). Supporting this, our results show that $\mathrm{Nb}$ fails to alter long-lived BCG-specific pulmonary CD4 T-cell memory and cytokine responses.

We also confirm the contribution of the IL- $4 \mathrm{R} \alpha$ during $\mathrm{Nb}-\mathrm{M}$. bovis BCG co-infection by showing that IL-4-R $\alpha^{-1-}$ knockout mice display an even further reduction in pulmonary mycobacterial burden compared with the corresponding infection groups in $\mathrm{BALB} / \mathrm{c}$ mice. In addition, the pulmonary mycobacterial burden in IL-4- $\mathrm{R} \alpha^{-1-}$ co-infected mice remained significantly reduced. Additionally, these findings also indicate that the enhanced pulmonary mycobacterial clearance observed in co-infected mice occur via a mechanism independent of IL- $4 \mathrm{R} \alpha$ signaling. Given the crucial role of AMs demonstrated in our co-infection model, it is tempting to speculate that in IL-4-R $\alpha^{-/-}$mice, AMs are preferentially activated to a classically activated phenotype in the presence of a helminth-induced type- 1 and type- 2 cytokine environment due to the loss of signaling via the IL- $4 \mathrm{R} \alpha$, facilitating enhanced mycobacterial control in co-infected mice. This closely reflects results reported by Potian et al. ${ }^{19}$ that reported decreased pulmonary mycobacteria in $N b-M$. $t b$ co-infected IL- $4 \mathrm{R} \alpha^{-1-}$ mice adoptively transferred with IL- $4 \mathrm{R} \alpha^{-1-}$ macrophages, compared with those receiving wild-type macrophages. ${ }^{19}$

Several hookworm infections, such as A. lumbricoides and Necator americanus, involve parasite migration through the lung. This process is largely asymptomatic in humans but may also be associated with acute respiratory distress, bronchial hyper-reactivity, asthma, and other chronic pulmonary conditions. ${ }^{23,51,52}$ Such chronic lung conditions have long been associated with enhanced risk for developing $\mathrm{TB} .{ }^{53}$ Our finding of exacerbated emphysematous alveolar dilatation in the lungs of co-infected mice of the "late" infection protocol may indicate that exposure to both helminth and mycobacterial infections can disrupt the ability of the lung to control chronic lung pathologies. We suggest this could be a consequence of impaired macrophage-driven tissue repair due to co-induction of $\mathrm{CAMs}^{26,54,55}$ or increased neutrophilia inducing the emphysematous phenotype in co-infected mice. ${ }^{56}$

Although the outcome of chronic helminth-mycobacterial coinfections remains to be examined, the work presented here established that previous acute infection with a helminth parasite can transiently improve immunity to a mycobacterial infection. This increased protection was associated with heightened innate 
immune cell responses and accelerated presence of activated $\mathrm{CD}^{+}{ }^{+} \mathrm{T}$ cells in the lungs of $\mathrm{Nb}$-infected mice. Our study reaffirms the prominent role of the innate immune response, especially AMs, in the protection against mycobacterial infections, and also the requirement of activated $\mathrm{CD} 4^{+} \mathrm{T}$ cells to sustain the macrophage-mediated protection against $M$. bovis BCG. These findings could assist in better understanding of the initial stages of mycobacterial pathogenesis and immediate consequences of acute hookworm co-infection.

\section{METHODS}

Animals. Six-to-eight-week-old specified pathogen-free (SPF) female BALB/c and IL-4 receptor-alpha knock-out (BALB/c genetic background) mice were used in all the experiments. Animals were obtained from the University of Cape Town (UCT) Animal Breeding Facility. All procedures were performed in BSL-2 animal facilities at the Universities of Stellenbosch (SU) and Cape Town (UCT). Procedures were approved by the respective Laboratory Animal Ethics Boards (Project licenses: P09/02/006 (SU); 009/ 037(UCT)).

M. bovis BCG infections. $M$. bovis BCG Pasteur was propagated in Middlebrook 7H9 broth (BD Biosciences, San Jose, CA), supplemented with $0.2 \%$ glycerol (Merck, Whitehouse Station, NJ), 0.05\% Tween 80 (Sigma-Aldrich, St Louis, MO), and 10\% oleic acid-albumindextrose-catalase (BD Biosciences) at $37^{\circ} \mathrm{C}$. M. bovis BCG cultures at logarithmic growth phase $\left(\mathrm{OD}_{600}=0.7-0.8\right)$ were used for infections. Mice were infected with $20 \mu \mathrm{l} 2.5 \times 10^{5} \mathrm{CFU}$ of BCG IN; control groups received $20 \mu \mathrm{l}$ sterile $1 \times \mathrm{PBS}$ (phosphate-buffered saline; Lonza, Walkersville, MD). The inoculum was confirmed $24 \mathrm{~h}$ post BCG infection by collecting the lungs of five mice. Mycobacterial proliferation in murine lungs was assessed by serial dilutions of homogenized organs plated out on Middelbrook 7H11 (Difco, Detroit, MI) agar plates, supplemented with $0.2 \%$ glycerol, and $10 \%$ oleic acid-albumin-dextrose-catalase. Plates were incubated for 3-4 weeks at $37^{\circ} \mathrm{C}$ whereupon CFU were counted manually.

Nb infections. Mice were infected sub-cutaneously with $500 \mathrm{~L} 3 \mathrm{Nb}$ parasites. $^{57}$

Co-infection experimental design. In all, 5-8 mice/experimental group were infected IN with $M$. bovis BCG at day 5 ("early infection protocol") or day 14 ("late infection protocol") post $\mathrm{Nb}$ infection. Control groups of $\mathrm{Nb}$-only or BCG-only-infected mice and uninfected mice were also used. Mice were killed at days 2,8 , or 14 post $M$. bovis BCG infection.

Preparation of single-cell suspension from the lungs, spleens, and lymphoid tissues. Single-cell suspensions of the isolated lungs, spleens, and MLN were prepared as described in ${ }^{58}$ Briefly, tissues were digested for $30 \mathrm{~min}$ at $37^{\circ} \mathrm{C}$ in RPMI 1640 (GIBCO, Grand Island, NY; Invitrogen, Carlsbad, CA) containing $100 \mu \mathrm{g} \mathrm{ml}^{-1}$ collagenase (Type IA, Sigma-Aldrich) and passaged through $70-\mu \mathrm{m}$ filters (BD Biosciences). Cells were resuspended in buffered ammonium sulfate (ACK buffer; $0.1 \mathrm{~mm}$ EDTA (Merck), $10 \mathrm{~mm} \mathrm{KHCO}_{3}$ (Merck), $150 \mathrm{~mm}$ $\mathrm{NH}_{4} \mathrm{Cl}$ (Merck) to lyse erythrocytes and then washed and resuspended in RPMI 1640.

Flow-cytometry. Lung cells were stained using antibody combinations of CD4 (clone: L3T4), CD44 (IM7), Thy1.1, CD62L (L-selectin); CD11c (HL3), Gr1, and CD11b (M1/70), conjugated with the following fluorochromes; phycoerythrin, allophycocyanin, fluorescein isothiocyanate, and peridinin chlorophyl protein from Biolegend (San Diego, CA) or BD Biosciences. In brief, cells were washed and resuspended in ice cold FACS (fluorescence-activated cell sorter) Buffer $(1 \times$ PBS (Lonza)) containing $2 \%$ fetal bovine serum
(Sigma-Aldrich), and each sample was incubated with each antibody for $20 \mathrm{~min}$ at $4{ }^{\circ} \mathrm{C}$. Cells were washed with ice cold FACS buffer and acquisitions performed using a FACS Calibur flow cytometer (BD Biosciences). Data were captured using Cell Quest software (BD Biosciences) and analyzed using FlowJo software (v 7.6.5, Tree Star, Ashland, OR).

AM enrichment. AM-enriched fractions were generated from the lung single-cell suspensions using either magnetic bead cell separation or macrophage adherence. ${ }^{59}$ In brief, total lung cells from individual samples were seeded in tissue culture plates and maintained in macrophage medium consisting of RPMI 1640 (GIBCO, Invitrogen) supplemented with $2 \mathrm{~mm}$ L-glutamine (GIBCO, Invitrogen) and 3\% fetal bovine serum (Sigma-Aldrich) for $3 \mathrm{~h}$ at $37^{\circ} \mathrm{C}$ with $5 \% \mathrm{CO}_{2}$. Nonadherent cells were removed by washing with pre-warmed Hank's Balanced Salt Solution (Sigma-Aldrich). Monolayers of adherent macrophages were dislodged with ice cold $1 \times \mathrm{PBS}$ without $\mathrm{Ca}++$ and $\mathrm{Mg}++$ (Lonza) containing $2 \mathrm{~mm}$ EDTA (Sigma-Aldrich) for $20 \mathrm{~min}$ at $4{ }^{\circ} \mathrm{C}$. Magnetic cell separation of AMs was achieved by positive selection with CD11c Mouse Microbeads kit (Miltenyi Biotec $\mathrm{GmbH}$, Bergisch, Gladbach, Germany). AMs were resuspended in macrophage medium for cell counting and viability determination. Macrophage enrichment was determined by DiffQuick staining of cytospin samples. Purity of AM fractions as determined by flow cytometry ranged between $78 \%$ and $89 \%$.

Pulmonary CD4 T-cell enrichment. CD4 ${ }^{+} \mathrm{T}$ cells were isolated from the pulmonary single-cell suspensions by negative selection using "untouched" mouse CD4 ${ }^{+}$T Cell MACS Isolation kit (Miltenyi Biotec) according to manufacturer's instructions. The purity of enriched $\mathrm{CD}_{4}{ }^{+}$T-cell fractions was determined by flow cytometry after labeling the isolated cells with fluorescein isothiocyanateconjugated CD4 monoclonal antibody. The average purity of $\mathrm{CD} 4{ }^{+}$fractions were $82 \%$.

In vitro $M$. bovis BCG phagocytosis assay. Phagocytosis assays were performed as per ${ }^{60}$ with slight modifications. AMs were resuspended in macrophage medium at $1 \times 10^{6} \mathrm{cells}^{-1}$ and infected with M. bovis BCG at a multiplicity of infection of 10:1 (BCG: AM ratio) for $3 \mathrm{~h}$ or $20 \mathrm{~h}$ at $37^{\circ} \mathrm{C}, 5 \% \mathrm{CO}_{2}$ (Thermo Scientific, Waltham, MA). Following infection, adherent macrophages were washed and lysed at $4{ }^{\circ} \mathrm{C}$ for $10 \mathrm{~min}$ in $\mathrm{dH}_{2} \mathrm{O}$ with $0.25 \%$ sodium dodecyl sulfate (SigmaAldrich). PBS/Tween 80 (Lonza/Sigma-Aldrich) was added and AMs further disrupted by pipetting. Intracellular $M$. bovis BCG burdens from lysed macrophages were determined by CFU enumeration as described above.

Arginase assay. AM-specific arginase (units per liter, $\mathrm{Ul}^{-1}$ ) activity was determined by a microplate test kit measuring conversion of arginine to urea by arginase according to manufacturer's instructions (Quantichrom, Arginase Assay Kit; BioAssay Systems, Hayward, CA).

In-vivo adoptive transfer. Donor mice were infected with $\mathrm{Nb}$ for 5 days or left uninfected and AMs $\left(1 \times 10^{5}\right)$ isolated as described above. AMs were resuspended in $20 \mu \mathrm{l} 1 \times$ PBS (Lonza) and applied to the nostrils of the recipient mouse 1 day before and 1 day after a M. bovis BCG infection. IN cell transfers to recipient mice were performed under light anesthesia. Pulmonary CFUs were enumerated 2 weeks later.

In vitro pathogen-specific and non-specific cell stimulations. Spleen, lung, and MLN cells $\left(2.5 \times 10^{6} \mathrm{ml}^{-1}\right)$ were stimulated for 4 days with BCG at a bacilli ratio of $5: 1$ in $5 \% \mathrm{CO}_{2}$ at $37^{\circ} \mathrm{C}$. AMs $\left(1 \times 10^{6} \mathrm{ml}^{-1}\right)$ or pulmonary CD4 T cells $\left(5 \times 10^{5} \mathrm{ml}^{-1}\right)$ were stimulated non-specifically in vitro with $50 \mathrm{ng} \mathrm{ml}^{-1}$ phorbol $12-\mathrm{myr}$ istate 13-acetate (Sigma-Aldrich) and $1 \mathrm{\mu g} \mathrm{ml}^{-1}$ Ionomycin (SigmaAldrich) for $6 \mathrm{~h}$ at $37^{\circ} \mathrm{C}$ and $5 \% \mathrm{CO}_{2}$. Unstimulated control wells were included for each sample to serve as negative background values, 
and phytohemagglutinin $\left(20 \mu \mathrm{g} \mathrm{ml}^{-1}\right)$-stimulated samples provided positive controls. Cytokine readouts of each condition were corrected for background values by calculating average cytokine concentration from negative controls and subtracting this value from stimulated values.

Ex-vivo cell-specific cytokine analysis. IFN- $\gamma$ and IL-13 ELISAs were performed according to manufacturer's recommendations (eBioscience, San Diego, CA). Multiplex bead array assay (xMAP; Millipore, Billerica, MA) was used for detection and quantification of the cytokines: IFN- $\gamma$, TNF- $\alpha$, GMCSF, IL-12, IL-5, IL-4, IL-10, IL-13, and IL-17. Cytokine concentration measurements were checked against internal quality controls, and serial dilutions of supplied cytokine controls were prepared according to the manufacturer's instructions to generate standard curves by the Bio-Plex Manager v.4.1.1.software (Bio-Rad, Hercules, CA).

Cytospin preparations. Cytospin slides were prepared by resuspending total viable lung cell suspensions to a concentration of $1 \times 10^{5}$ cells ml $^{-1}$ in RPMI 1640 (GIBCO, Invitrogen). Cells were centrifuged at $95 \times g$ for $7 \mathrm{~min}$ in cytospin chambers (Cytospin-2, Shandon Southern Products, Cheshire, UK) onto glass microscope slides (Erie Scientific, Portsmouth, NH). Slides were air dried and stained using RapiDiff Stain Set (Clinical Sciences Diagnostics, Johannesburg, South Africa).

Histology. Right upper lung lobes were collected from individual mice, fixed in $10 \%$ buffered formalin, and embedded into paraffin blocks. Sections $(3-5 \mu \mathrm{m})$ were cut and stained with haematoxylin and eosin. Histopathological analyses were modified from the procedure followed by Hamelin et al. ${ }^{61}$ for semi-quantitative measurements of pulmonary inflammation and alveolar dilation. Briefly, total area of lung parenchyma $(0-100 \%)$ and degree $(0-10)$ of inflammation were scored. These parameters were determined in duplicate in a blinded fashion for each lung section in three lung regions: perivascular, peribronchial and lung interstitial area. Scores were combined to generate a total inflammation score for the lungs of each mouse per group. Lungs from naive mice were used as negative controls, with a score of 0 assigned in all the categories.

Statistical analysis. Graphs and statistical calculations were performed using Graph Pad Prism (version 5.02, GraphPad Software, San Diego, CA). Non-parametric analyses, Mann-Whitney $U$ tests, and one-way ANOVA tests (with Bonferroni's post-hoc) were used to determine significant differences between time points, and statistically significant differences were judged as $P \leqslant 0.05$. Data were presented as mean and s.e.m.

SUPPLEMENTARY MATERIAL is linked to the online version of the paper at http://www.nature.com/mi

\section{ACKNOWLEDGEMENTS}

We acknowledge the staff of the SU and UCT animal facilities for backup animal care; Nasiema Allie and Ronnie Dreyer for technical support. Financial support was provided by the Deutsche Forschungsgemeinschaft (DFG, IRTG-1522) and National Research Foundation (NRF) of South Africa.

\section{AUTHOR CONTRIBUTIONS}

GW, WGCH, and NDP conceived and designed the experiments. NDP, LK, and LT performed the experiments. NDP and WGCH analyzed the data. GW, FB, WGCH, and PDvH contributed reagents/materials. NDP and WGCH wrote the paper. GW, PDvH, LK, and FB critically reviewed the manuscript.

\section{DISCLOSURE}

The authors declared no conflict of interest.

\section{REFERENCES}

1. Mauad, T. et al. Lung pathology in fatal novel human influenza $A(H 1 N 1)$ infection. Am. J. Respir. Crit. Care Med. 181, 72-79 (2010).

2. Iverson, A.R. et al. Influenza virus primes mice for pneumonia from Staphylococcus aureus. J. Infect. Dis. 203, 880-888 (2011).

3. Brooker, S., Bethony, J. \& Hotez, P.J. Human hookworm infection in the 21st Century. Adv. Parasitol. 58, 197-288 (2004).

4. Savioli, L. \& Albonico, M. Focus: soil-transmitted helminthiasis. Nat. Rev. Microbiol. 2, 618-619 (2004).

5. Maizels, R.M. et al. Helminth parasites-masters of regulation. Immunol. Rev. 201, 89-116 (2004).

6. Brooker, S., Hotez, P.J. \& Bundy, D.A.P. The global atlas of helminth infection: mapping the way forward in neglected tropical disease control. PLoS Negl. Trop. Dis. 4, e779 (2010).

7. Lienhardt, C. et al. Active tuberculosis in Africa is associated with reduced Th1 and increased Th2 activity in vivo. Eur. J. Immunol. 32, 1605-1613 (2002).

8. Jackson, J.A., Friberg, I.M., Little, S. \& Bradley, J.E. Review series on helminths, immune modulation and the hygiene hypothesis: immunity against helminths and immunological phenomena in modern human populations: coevolutionary legacies?. Immunology 126, 18-27 (2009).

9. Kidd, P. Th1/Th2 balance: the hypothesis, its limitations, and implications for health and disease. Altern Med. Rev. 8, 223-246 (2003).

10. Moreau, E. \& Chauvin, A. Immunity against helminths: interactions with the host and the intercurrent infections. J. Biomed. Biotechnol. 2010, 1-10 (2010).

11. Elias, D., Akuffo, H. \& Britton, S. Helminthes could influence the outcome of vaccines against TB in the tropics. Parasite Immunol. 28, 507-513 (2006).

12. Elias, D., Britton, S., Kassu, A. \& Akuffo, H. Chronic helminth infections may negatively influence immunity against tuberculosis and other diseases of public health importance. Expert Rev. Anti-infective Ther. 5, 475-484 (2007).

13. Rook, G.A.W. Th2 cytokines in susceptibility to tuberculosis. Curr. Mol. Med. 7, 327-337 (2007).

14. Adams, J.F. et al. Decline in total serum lgE after treatment for tuberculosis. Lancet 353, 2030-2033 (1999).

15. Elias, D. et al. Schistosoma mansoni infection reduces the protective efficacy of BCG vaccination against virulent Mycobacterium tuberculosis. Vaccine 23, 1326-1334 (2005).

16. Elias, D., Akuffo, H., Thors, C., Pawlowski, A. \& Britton, S. Low dose chronic Schistosoma mansoni infection increases susceptibility to Mycobacterium bovis BCG infection in mice. Clin. Exp. Immunol. 139, 398-404 (2005).

17. Elias, D. et al. Effect of deworming on human $T$ cell responses to mycobacterial antigens in helminth-exposed individuals before and after bacille Calmette-Guérin (BCG) vaccination. Clin. Exp. Immunol. 123, 219-225 (2001).

18. Erb, K.J., Trujillo, C., Fugate, M. \& Moll, H. Infection with the helminth nippostrongylus brasiliensis does not interfere with efficient elimination of mycobacterium bovis BCG from the lungs of mice. Clin. Diagn. Lab. Immunol. 9, 727-730 (2002).

19. Potian, J.A. et al. Preexisting helminth infection induces inhibition of innate pulmonary anti-tuberculosis defense by engaging the IL-4 receptor pathway. J. Exp. Med. 208, 1863-1874 (2011).

20. Fulton, S.A., Martin, T.D., Redline, R.W. \& Henry Boom, W. Pulmonary immune responses during primary mycobacterium bovis-Calmette-Guerin bacillus infection in C57BI/6 mice. Am. J. Respir. Cell Mol. Biol. 22, 333-343 (2000).

21. Camberis, M., Le Gros, G. \& Urban, J. Jr Animal model of Nippostrongylus brasiliensis and Heligmosomoides polygyrus. Curr. Protoc. Immunol. Chapter 19, Unit 19.12 (2003)

22. Loukas, A. \& Prociv, P. Immune responses in hookworm infections. Clin. Microbiol. Rev. 14, 689-703 (2001).

23. Marsland, B.J., Kurrer, M., Reissmann, R., Harris, N.L. \& Kopf, M. Nippostrongylus brasiliensis infection leads to the development of emphysema associated with the induction of alternatively activated macrophages. Eur. J. Immunol. 38, 479-488 (2008).

24. Ramaswamy, K., De Sanctis, G.T., Green, F. \& Befus, D. Pathology of pulmonary parasitic migration: morphological and bronchoalveolar cellular 
responses following Nippostrongylus brasiliensis infection in rats. J. Parasitol. 77, 302-312 (1991).

25. Marsland, B.J., Camberis, M. \& Le Gros, G. Secretory products from infective forms of Nippostrongylus brasiliensis induce a rapid allergic airway inflammatory response. Immunol. Cell Biol. 83, 40-47 (2005).

26. Reece, J.J., Siracusa, M.C. \& Scott, A.L. Innate immune responses to lung-stage helminth infection induce alternatively activated alveolar macrophages. Infect. Immun. 74, 4970-4981 (2006).

27. Lawrence, R.A., Gray, C.A., Osborne, J. \& Maizels, R.M. Nippostrongylus brasiliensis: cytokine responses and nematode expulsion in normal and IL4-deficient mice. Exp. Parasitol. 84, 65-73 (1996).

28. Leversen, N.A., Sviland, L., Wiker, H.G. \& Mustafa, T. Long-term persistence of BCG Pasteur in lungs of C57BL/6 mice following intranasal infection. Scand. J. Immunol. 75, 489-499 (2012).

29. Mills, C.D., Kincaid, K., Alt, J.M., Heilman, M.J. \& Hill, A.M. M-1/M-2 macrophages and the Th1/Th2 paradigm. J. Immunol. 164, 6166-6173 (2000).

30. Bot, A., Smith, K.A. \& von Herrath, M. Molecular and cellular control of T1/T2 immunity at the interface between antimicrobial defense and immune pathology. DNA Cell Biol. 23, 341-350 (2004).

31. Gallegos, A.M., Pamer, E.G. \& Glickman, M.S. Delayed protection by ESAT-6-specific effector CD4 + T cells after airborne M. tuberculosis infection. J. Exp. Med. 205, 2359-2368 (2008).

32. Gu, N. et al. Intelectin is required for IL-13-induced monocyte chemotactic protein-1 and -3 expression in lung epithelial cells and promotes allergic airway inflammation. Am. J. Physiol. Lung Cell. Mol. Physiol. 298, L290-L296 (2010).

33. Jenkins, S.J. et al. Local macrophage proliferation, rather than recruitment from the blood, is a signature of $\mathrm{TH} 2$ inflammation. Science 332 , 1284-1288 (2011).

34. Classen, A., Lloberas, J. \& Celada, A. Macrophage activation: classical versus alternative. Methods Mol. Biol. 531, 29-43 (2009).

35. Hartgers, F.C. \& Yazdanbakhsh, M. Co-infection of helminths and malaria: modulation of the immune responses to malaria. Parasite Immunol. 28, 497-506 (2006).

36. Brown, M. et al. Schistosoma mansoni, nematode infections, and progression to active tuberculosis among HIV-1-infected Ugandans. Am. J. Trop. Med. Hyg. 74, 819-825 (2006).

37. Hoeve, M.A. et al. Plasmodium chabaudi limits early Nippostrongylus brasiliensis-induced pulmonary immune activation and Th2 polarization in co-infected mice. BMC Immunol. 10, 602009).

38. Gordon, S. \& Martinez, F.O. Alternative activation of macrophages: mechanism and functions. Immunity 32, 593-604 (2010).

39. Silva, M.T., Silva, M.N. \& Appelberg, R. Neutrophil-macrophage cooperation in the host defence against mycobacterial infections. Microb. Pathog. 6, 369-380 (1989).

40. Silva, M.T. When two is better than one: macrophages and neutrophils work in concert in innate immunity as complementary and cooperative partners of a myeloid phagocyte system. J. Leukoc. Biol. 87, 93-106 (2010).

41. Tan, B.H. et al. Macrophages acquire neutrophil granules for antimicrobial activity against intracellular pathogens. J. Immunol. 177, 1864-1871 (2006).

42. Mackaness, G.B. The influence of immunologically committed lymphoid cells on macrophage activity in vivo. J. Exp. Med. 129, 973-992 (1969).
43. Sieve, A.N. et al. A novel IL-17-dependent mechanism of cross protection: respiratory infection with mycoplasma protects against a secondary listeria infection. Eur. J. Immunol. 39, 426-438 (2009).

44. Wolf, A.J. et al. Initiation of the adaptive immune response to Mycobacterium tuberculosis depends on antigen production in the local lymph node, not the lungs. J. Exp. Med. 205, 105-115 (2008).

45. Chackerian, A.A., Alt, J.M., Perera, T.V., Dascher, C.C. \& Behar, S.M. Dissemination of Mycobacterium tuberculosis is influenced by host factors and precedes the initiation of T-cell immunity. Infect. Immun. 70, 4501-4509 (2002).

46. Gonzalez-Juarrero, M. et al. Temporal and spatial arrangement of lymphocytes within lung granulomas induced by aerosol infection with Mycobacterium tuberculosis. Infect. Immun. 69, 1722-1728 (2001).

47. Huffman, J.A., Hull, W.M., Dranoff, G., Mulligan, R.C. \& Whitsett, J.A. Pulmonary epithelial cell expression of GM-CSF corrects the alveolar proteinosis in GM-CSF-deficient mice. J. Clin. Invest. 97, 649-655 (1996).

48. Shibata, Y. et al. GM-CSF regulates alveolar macrophage differentiation and innate immunity in the lung through PU.1. Immunity 15, 557-567 (2001).

49. Higgins, D.M. et al. Relative levels of M-CSF and GM-CSF influence the specific generation of macrophage populations during infection with Mycobacterium tuberculosis. J. Immunol. 180, 4892-4900 (2008).

50. Peyron, P. et al. Foamy macrophages from tuberculous patients' granulomas constitute a nutrient-rich reservoir for $M$. tuberculosis persistence. PLoS Pathog. 4, e10002042008).

51. Vijayan, V.K. Tropical parasitic lung diseases. Indian J. Chest Dis. Allied Sci. 50, 49-66 (2008).

52. Donnelly, S., Dalton, J.P. \& Loukas, A. Proteases in helminth- and allergeninduced inflammatory responses. Chem. Immunol. Allergy 90, 45-64 (2006).

53. Inghammar, M. et al. COPD and the risk of tuberculosis-a populationbased Cohort study. PLoS ONE 5, e10138 (2010).

54. Varin, A., Mukhopadhyay, S., Herbein, G. \& Gordon, S. Alternative activation of macrophages by IL-4 impairs phagocytosis of pathogens but potentiates microbial-induced signalling and cytokine secretion. Blood 115, 353-362 (2010).

55. Krysko, O. et al. Alternatively activated macrophages and impaired phagocytosis of S. aureus in chronic rhinosinusitis. Allergy 66, 396-403 (2011).

56. Shapiro, S.D. et al. Neutrophil elastase contributes to cigarette smokeinduced emphysema in mice. Am. J. Pathol. 163, 2329-2335 (2003).

57. Mearns, H. et al. Interleukin-4-promoted T helper 2 responses enhance Nippostrongylus brasiliensis-induced pulmonary pathology. Infect. Immun. 76, 5535-5542 (2008).

58. Anis, M.M., Fulton, S.A., Reba, S.M., Harding, C.V. \& Boom, W.H. Modulation of naive CD4 + T-cell responses to an airway antigen during pulmonary mycobacterial infection. Infect. Immun. 75, 2260-2268 (2007)

59. Hiraoka, M. et al. Lysosomal phospholipase A2 and phospholipidosis. Mol. Cell. Biol. 26, 6139-6148 (2006).

60. Wiley John \& Sons Current Protocols in Immunology_Current Protocols. At $<$ http://cda.currentprotocols.com/WileyCDA/CPTitle/isbn-0471522767, descCd-tableOfContents.html > .

61. Hamelin, M.-Ė. et al. Pathogenesis of human metapneumovirus lung infection in BALB/c mice and cotton rats. J. Virol. 79, 8894-8903 (2005). 